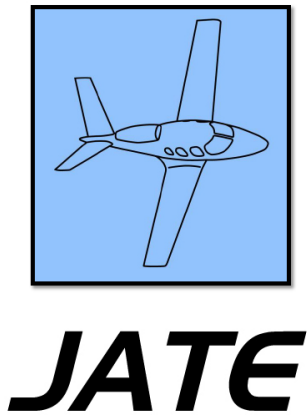

Journal of Aviation Technology and Engineering 7:2 (2018) 42-56

\title{
Teaching the Next Generation of Researchers: An Inquiry into Aviation Research Education
}

\author{
David C. Ison \\ Embry-Riddle Aeronautical University-Worldwide
}

\begin{abstract}
Research in aviation fields has become increasingly important to institutions and their faculties. Expectations to conduct such research have escalated, with tenure and employment decisions often hanging on evidence of research skill and advanced educational attainment. Considering the importance of research to aviation higher education, this study investigated how research skills are conveyed to undergraduate and graduate aviation students. Further, the subjects and methods of instruction were evaluated. This inquiry was guided by content analysis. To bolster the findings of this study, a series of interviews with program directors and faculty teaching research courses were conducted to explore faculty perceptions of research education as well the as strengths and weaknesses of such education and the students enrolled in research courses.
\end{abstract}

Keywords: research, education, aviation, content analysis, interviews, research-led education

The ability to conduct research is a skill that is essential for every scholar. For any field of study to move forward and discover new and innovative knowledge, research must be conducted. The non-engineering aviation field is no exception. Further, this research must be directed in a sound manner so as not to come to flawed conclusions. Perhaps most important is the ability to disseminate the findings of such research in coherent, succinct writing. Thus, it is essential that there be a well-educated, skilled, capable assemblage of aviation researchers to provide for the continued improvement of the field and expand the associated knowledge base (Johnson, Hamilton, Gibson, \& Hanna, 2006; Wright, 2005).

The recognition of the importance of research has frequently appeared in a wide range of literature. Wright (2005) has stated that research was the "lifeblood, hallmark or cornerstone in the development of a profession" (p. 4). Anderson (2011) has stated:

Research is an important activity in the business and scientific communities as well as in virtually every academic discipline... In higher education, learning how to conduct valid research prepares students for their future professional lives, and it certainly enhances the learning process. (Section A)

So not only does research education help students when they enter real-world professions, but it is also critical to those individuals who wish to pursue graduate education because research becomes more and more important the further one proceeds beyond a bachelor's degree.

All correspondence concerning this article should be directed to David C. Ison at isond46@erau.edu. 
However, one challenge to aviation research education is that "only in the last twenty years...non-engineering aviation scholarly research journals began to appear. Before the recent emergence of new scholarly journals, aviation education researchers had only a limited number of publishing opportunities available to them" (Johnson et al., 2006, p. 82). Thus, aviation research has only recently become a priority in the field. This fact is reinforced by the statement that the "lack of definition and recent emergence of aviation peer-reviewed journals has led some to define aviation education as an "emerging discipline"" (Johnson et al., 2006, p. 83). In a sense, aviation education has been expected to prove itself as a viable and productive research community: "as aviation education establishes itself in academia, it must continue to advance the discipline by creating a rich depository characterized by scholarship and inquiry" (Johnson et al., 2006, p. 83). As such, even in light of its neophyte presence, the expectations of quality contributions have been increasing in recent years. Moreover, current and future aviation faculties are facing increasing pressure to conduct and report research to the academic and industry communities (Ison, 2011).

The problem is that there must be a sound research education system in place to encourage inquiry and to produce excellence in results. Unfortunately, many researchers lack the skills necessary to perform competent inquiry (Pato \& Pato, 2001). Ning, Murphy, and Jinks (2010) stated that a "lack of knowledge and skills in relation to research methodologies appeared to be important inhibitors [to conducting studies], with educators saying they needed more help to develop their research skills" (p. 539). Advanced research was not a priority for non-engineering aviation faculty until recently. This was evident by the fact that most aviation faculty do not hold a doctorate and, in a study by Ison (2009), only about $10 \%$ of professional pilot education faculty were found to have some form of a doctorate degree. However, this appears to be changing, albeit slowly. In an analysis of aviation faculty employment advertisements, a master's degree was the minimum educational requirement in over $71 \%$ of the positions advertised, but a doctoral degree was the employment preference in more than $66 \%$ of the positions (Ison, 2009). The difference between the rate of preference for a doctorate and the prevalence of such a degree among faculty at those institutions was found to be statistically significant; thus, the expectations for advanced training in research appear to be on the rise (Ison, 2011). A likely contributor to this problem is the fact that the non-engineering aviation area of study only gained its own, focused $\mathrm{PhD}$ program in 2009 (Embry-Riddle Aeronautical University, 2009).

Because of the importance of research skills and performance in a wide range of fields, there has been a significant amount of inquiry into research education. While entryor lower-level research courses understandably focus on an introduction to methods, successful conveyance of the knowledge and talents required of capable, proficient researchers was reported to require a more hands-on, practical approach (Crull \& Collins, 2004; España, 2004; Ning, Murphy, \& Jinks, 2010; Pato \& Pato, 2001). For example, Healy, Jordan, Pell, and Short (2010) recognized that students are more engaged and benefit greatly when immersed in research conducted with faculty currently involved in such activities. The term research-led has been used to describe the approach where students are compelled to shift from being passive participants to active practitioners through the use and practice of authentic, applied research skills (LaBeouf, 2011).

Pato and Pato (2001) have advocated for a building-block style approach to teaching research skills. In their study, initially the students were introduced to general research methods, then shown examples of research in the format of studies and journal articles, and subsequently asked to write up their findings. Also, the students were instructed how to pursue publication and critique peer research. Upchurch, Brosnan, and Grimes (2002) promoted a similar construction of competencies beginning with teaching students how to find literature using modern databases. Next, the students were required to examine existing research and build the foundations of a literature review. Additional tasks were assigned to gain familiarity with research design, appropriate data collection, and analysis of findings.

España (2004) explored this issue from a more academic perspective by advocating for research-led education based on the hierarchy of critical-thinking skill development. Basic researcher courses fall into the first level of theoretical development called dualism. At this stage, students rely heavily on the instructor for guidance as to what is correct or incorrect. Often such lower level courses also fall into the multiplicity stage where students know there are many alternatives but are not able to distinguish which is the best or most appropriate to choose. In more advanced research coursework, learners reach the contextual realism phase where they discover that their positions must be supported by extant literature (España, 2004). Research-led learning, at the highest level, requires the attainment of the dialectic stage where students interpret the results and thereby give meaning to the findings and provide new knowledge (España, 2004). Reaching the highest level is accepted to be impossible without applicatory tasks and practice (Crull \& Collins, 2004; España, 2004; LaBeouf, 2011; Ning et al., 2010; Pato \& Pato, 2001; Upchurch et al., 2002).

Taking the realism in research a step further, Crull and Collins (2004) supported confidence-boosting events such as poster sessions and conference participation. This step is perhaps too often minimalized. As Sullivan and Maxfield (2003) argued, it is a fundamental component of scientific socialization in which individuals are introduced to:

The standards of the [research] paradigm...through the teaching and writing of scholars who are already 
established in the field. Students are socialized to follow the central norms of the paradigm through their study with experienced instructors and the reading of scholarly work. Doctoral students are expected to internalize and embrace the elements of the paradigm if they wish to become a part of the scientific community. (p. 269)

Therefore, students of research can only expect to become practitioners by seeing and doing what actual researchers do and are expected to do within their field of study.

If the edification of researchers is essential for the proliferation of research, then knowledge of how and what research is taught is undoubtedly an indispensable piece of the process. Content analysis is a research method used to uncover common information in the literature. Sullivan and Maxfield (2003) conducted a content analysis of 54 doctoral research course syllabi. The method was justified as it provided for a logical means of evaluating course materials (Sullivan \& Maxfield, 2003). The documents were coded to identify course type, themes, and assignments.

$\mathrm{Lu}$ (2007) also used content analysis to evaluate 43 introductory doctoral-level syllabi for critical items such as frequency and quantity of contact time, textbooks, readings, objectives, topics, assignments, assessment tasks, ethics, plagiarism, and format/citation methods. Drisko (2008) used a mix of surveys and content analysis to examine how research was taught at the master's level in social work. A total of 48 syllabi and 57 surveys were collected. The content analysis of the syllabi was focused on research frequency/quantity of contact, methods taught, readings, and assignments. The survey was constructed of six descriptive questions focused on overall content, program construction, and the presence of practical application.

Identifying more information that can be gleaned from content analysis of syllabi has been helpful in identifying the complexities of research education. Ning et al. (2010) surveyed 72 healthcare research educators. They collected data on faculty attitudes and experiences concerning research. Only $22 \%$ had their research findings published, and just under $20 \%$ had participated in funded research. Only $37 \%$ of the faculty were likely or highly likely to volunteer to teach research. It indeed could potentially be detrimental to the teaching of research if those conducting such classes had limited experience in peer-reviewed research or funded projects. Further, if they were not interested in teaching the subject, this could theoretically have an adverse effect on the classroom environment (Ning et al., 2010).

There is clear evidence that research has recently become an increasingly important component of the non-engineering aviation field and to faculty within that field. The literature synthesis also indicates a growing level of expectation for the level of aviation faculty educational attainment and research skill (Ison, 2011). There is a range of studies on the evaluation of research education because of its critical nature to virtually all areas of study in higher education; however, there are few studies on both what and how research is taught in aviation (Ison, 2009; Johnson et al., 2006; Wright, 2005). This study addresses these gaps in the literature.

\section{Method}

This study entailed a content analysis of non-engineering aviation undergraduate and graduate research courses taught at University Aviation Association (UAA) member institutions. Additionally, interviews were conducted from which the resultant data were also analyzed with content analysis.

\section{Participants}

The most recent UAA institutional membership list was utilized to identify schools that are four-year institutions to be included in the study (UAA, 2012). A total of 63 aviation institutions were identified among which 18 offered graduate degrees. The institution websites and course catalogs were mined to identify research courses and major requirements at both the graduate and undergraduate levels. A purposive sample of 11 program directors/chairs/managers were selected to ensure a range of institution types (public and private), focus (aviation-oriented and liberal arts), as well as program size (from under 100 to 5,000 students). See Appendix A for the list of included institutions. Each was contacted to participate in the interview and course syllabi phase of this study.

\section{Materials and Procedure}

The first step in the analysis was to identify the type and number of institution-wide research-related courses. Next, the numbers of writing-specific courses within each program were quantified. Course descriptions were collected for each aviation-specific course identified that conveyed research methods or built research skills. These were then evaluated via content analysis. The content analysis process was modeled on the guidance provided by Berg (2007), Krippendorff (2004), Neuendorf (2002), and Okumus and Wong (2007). Additional theme identification strategies used in the research education literature served as a guide to this study (Drisko, 2008; Lu, 2007; Sullivan \& Maxfield, 2003). Further, the guidance of Riffe, Lacy, and Fico (2005) to use literature-based measures and create standardized coding sheets was utilized to properly manage the data. Initially, open coding was used to gain insight into the overarching themes within the course descriptions and syllabi (Berg, 2007). Mutually exclusive categories were defined by the guidance of Weber (1990). A final codebook was created to ensure the standardization of analysis across the data (Krippendorff, 2004; Neuendorf, 2001; Riffe et al., 2005). Additional guidance on codebook construction was garnered from a similar study on syllabi by Ison (2010). Before examining sample data, test coding was 
conducted on non-aviation-related research course materials (Weber, 1990).

To further supplement the findings of the content analysis, a series of brief interviews were conducted with the program directors or faculty teaching research courses. Contact data were collected from UAA program listings. The interview questions were constructed based upon existing studies on research education and were pilot tested on a group of non-participating aviation faculty (Crull \& Collins, 2004; España, 2004; LaBeouf, 2011, Ning et al., 2010; Pato \& Pato, 2001; Upchurch et al., 2002). These efforts resulted in a standardized interview protocol providing a semi-structured approach that will allow flexibility to probe for more detailed data from each (Berg, 2007; Kvale \& Brinkmann, 2008). The protocol was reviewed by a panel of education and aviation higher education faculty that fell outside the target sample. Feedback was integrated into the final draft of the protocols. Individuals were initially contacted by email to request their participation (Kvale \& Brinkmann, 2008). For those that agreed to participate, interviews were conducted via telephone due to the geographic distribution of faculty (Creswell, 2003). Responses were categorized by each question of the instrument. Each of these responses was analyzed via content analysis to identify themes and commonalities. The interview instrument is included in Appendix B. Free Mind software (http://freemind.sourceforge.net/wiki/index.php/Main_ Page) was used to map the themes identified in aviationspecific course descriptions.

\section{Operational Definitions}

For this research, the following operational definitions provided bounds for the study:

- Research: "research is simply the process of arriving at a dependable solution to a problem through the planned and systematic collection, analysis and interpretation of data" (Singh, 2006, p. 1).

- Research courses: classes that teach "methods that scholars in a given discipline use to ask and pursue research questions" (University of North Carolina, 2018, para. 4). Sample topics covered in such courses include "introduces the language of research, ethical principles and challenges, and the elements of the research process within quantitative, qualitative, and mixed methods approaches" (Thompson Rivers University, n.d., para. 1). Example course titles are introduction to research methods, research methods, qualitative research, quantitative research, statistics, and courses as part of writing and developing theses, dissertations, or capstones.

- Research methods: "the general approach the researcher takes in carrying out the research project...this approach dictates the particular tools the researcher selects" (Leedy \& Ormrod, 2010, p. 12). Examples of methods include, but are not limited to, descriptive research, correlation research, experimental research, nonexperimental research, quasi-experimental research, quantitative methods, qualitative methods, and mixed methods (Stangor, 2007; Weathington, Cunningham, \& Pittenger, 2010).

- Research skills: critical thinking, problem-solving, analysis, and dissemination. Examples of research skill building were students autonomously conducting research, analyzing data, and reporting findings in the form of prescribed documentation (e.g., theses, reports, capstone papers) (University of Sydney, 2012).

\section{Results}

\section{Research Courses}

Among the 63 undergraduate programs analyzed, 23 $(36.5 \%)$ included non-aviation research courses in their curricula while only three $(4.7 \%)$ had aviation-specific research-related courses. The mean number of non-aviation research courses per program was $0.51(S D=0.68)$, and the mean aviation-related research courses per program was $0.03(S D=0.17)$. Undergraduate programs had a mean of 1.67 writing courses $(S D=0.94)$. There were $11(17.4 \%)$ programs that had no required writing-intensive courses.

Of the 18 graduate programs that were identified, 15 $(83.3 \%)$ included non-aviation research-oriented courses, and eight $(44.4 \%)$ had aviation-specific research courses. The mean number of non-aviation research courses was $0.72(S D=1.42)$ and the mean aviation-related counterpart was $0.36(S D=0.96)$. All graduate programs had at least one requisite writing course, most commonly a capstone or thesis requirement. See Figures 1 and 2 for a summary of the research course type distribution among programs.

\section{Undergraduate research course themes}

Undergraduate research-related courses were concentrated in five subject areas. The most extensive grouping comprised courses with a mathematics/statistics program prefix. The remaining prefixes included English, business, psychology, and aviation-related. Figure 3 shows the distribution of course prefixes. The common theme among statistics-based courses was that the majority were "introduction to," "introductory," "elements of," "elementary," "understanding," or general classes on the subject. More focused statistics courses were identified, but were singular in numbers and included "economic," "business," and "experimental" statistics. Research-specific courses included the following key terms:

- Operational research

- Research methods

- College writing and research

- Introduction to writing and research

- Analysis, research, and documentation 


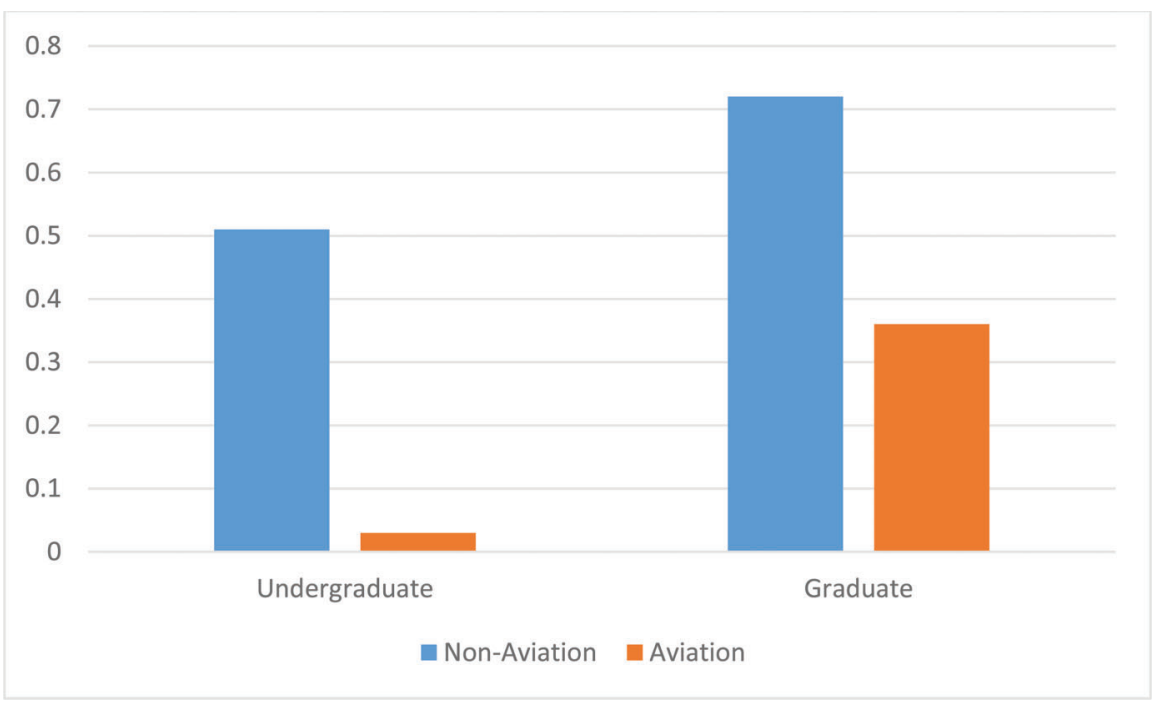

Figure 1. Percentage of programs with non-aviation-specific and aviation-specific research courses.

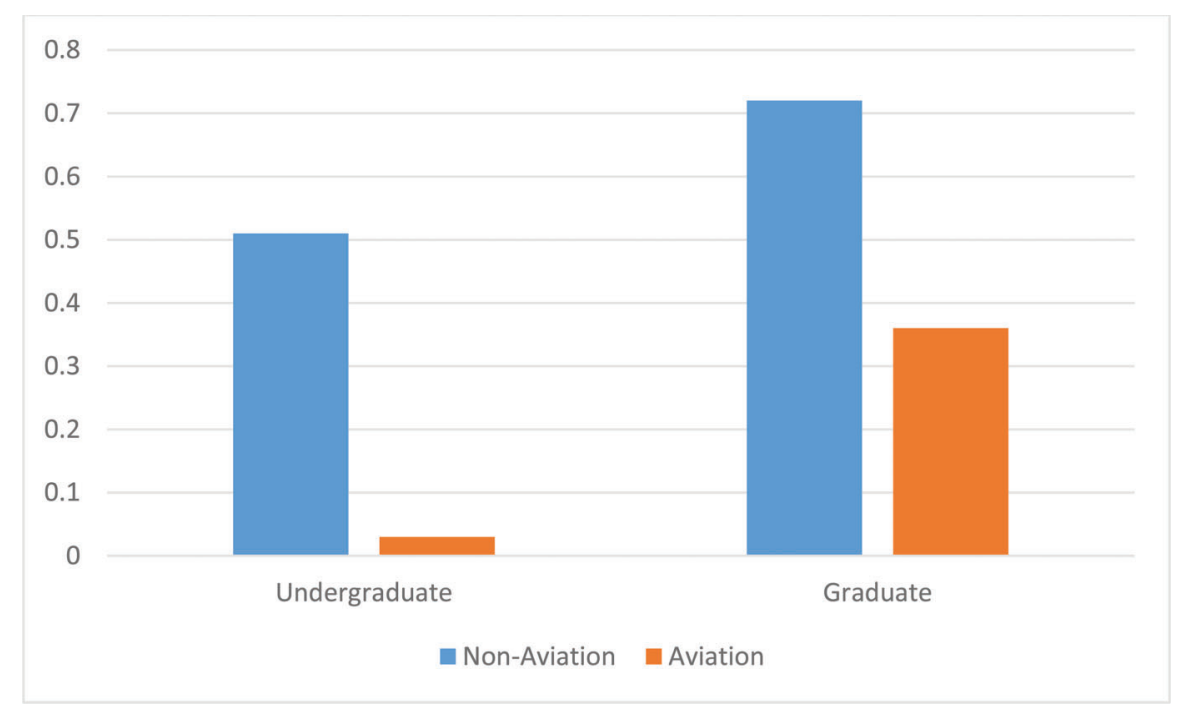

Figure 2. Mean number of non-aviation-specific and aviation-specific research courses per program.

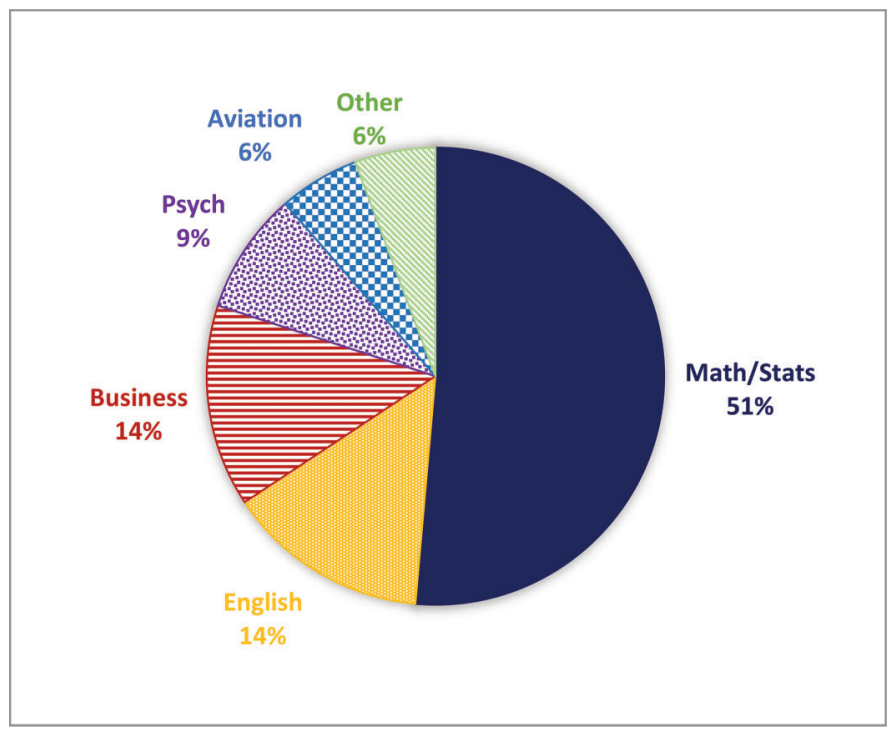

Figure 3. Distribution of undergraduate course program area prefixes. 
- Research and argumentative writing

- Business quantitative methods

- Library research skills.

Aviation-specific research courses were limited to "performance evaluation and measurement" and "research methods."

\section{Graduate research course themes}

Master's level research courses most commonly incorporated the title "research methods" of which the majority fell under aviation program prefixes (see Figure 4). Other course titles included:

- Quantitative methods

- Qualitative methods

- Statistical analysis

- Theoretical foundations of inquiry

- Experimental statistics

- Research in safety.

\section{Aviation Courses}

Aviation-specific research courses were more common at this level of study. Among master's aviation research courses were the following course titles:

- Research and statistics

- Advanced aviation research project

- Research methods in aviation

- Introduction to aviation research

- Applied statistics in aviation research

- Thesis research

- Applied research

- Case research

- Individual research in aviation
- Readings in aviation

- Analysis of aviation research.

Also, a variety of thesis or capstone courses existed at graduate institutions. At the doctoral level, more advanced courses were offered. These included:

- Advanced quantitative methods

- Applied multivariate statistics

- Mixed methods

- Advanced quantitative data mining

- Operations research

- Qualitative research

- ANOVA

- Multiple regression

- Multivariate statistics

- Qualitative and alternative methods

- Experimental design and research methods.

\section{Course description themes}

The course descriptions of the aviation courses were analyzed for themes. The data were grouped by undergraduate and graduate courses.

Undergraduate course description themes. The three aviation research courses identified in this study covered fundamental concepts and did not appear to explore any detailed research methods. One of the courses was described as "directed research on a topic not covered in organized classes." The other courses covered the following:

- Performance metrics and analysis

- Performance criteria from metrics

- Performance measurement

- Writing a research paper

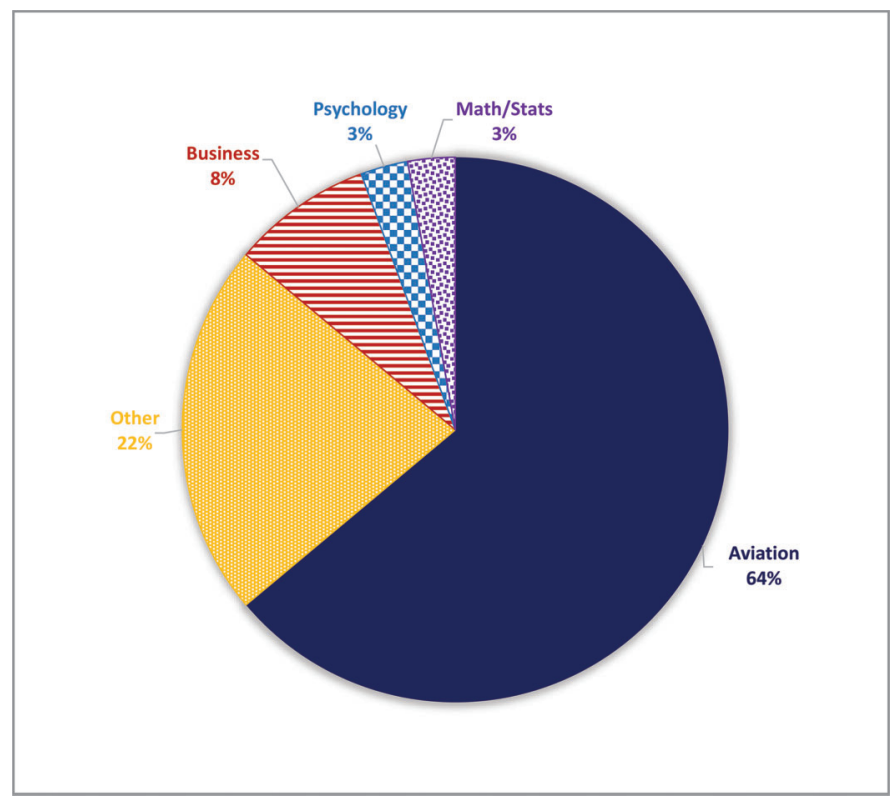

Figure 4. Distribution of graduate course program area prefixes. 
- Interpreting data

- Analyzing data

- Written and oral communications

- APA format.

Regarding tasks required in these courses, two required an in-depth term-type paper. The other course derived the course grade from three tests, a case analysis, and a presentation. No specific methods, statistical analysis, or other key research terms or tools were described or mentioned.

Graduate course description themes. There were 26 aviationspecific graduate courses analyzed. Course descriptions indicated content subject matter ranging from the very basic levels to particular course focus. A course titled with the word "research" generally mentioned the inclusion of research methods with some specifically identifying qualitative, quantitative, and mixed methods. Four (15.3\%) of these courses combined research methods and statistics. Among the 26 courses, eight (30.7\%) were titled with the word "statistics." See Figure 5 for the distribution summary.

During the thematic analysis of the courses, several common threads emerged among the descriptions. The following were the most commonly mentioned items:

- Research methods

- Quantitative methods

- Qualitative methods

- Research problem

- Statistics

- Parametric

- Non-parametric.
The remaining content of the course descriptions was somewhat scattered. Therefore, mind mapping software (Free Mind) was employed to develop a depiction of the chain of related subjects (see Figure 6).

\section{Undergraduate course syllabi}

Three undergraduate syllabi were collected. There were few common traits among the syllabi. Two required written tasks as well as oral presentations. One course mentioned the requirement to demonstrate digital communication. In terms of required graded activities, one syllabus noted that the entire grade for the course was based upon the completion of a research paper. Another course used a combination of scores on homework, exams, and quizzes, and class attendance for the course grade. The remaining course required students to take a comprehensive exam that was the only graded activity. One of the courses was highly statistically based. It covered statistical analysis software, sampling, parametric and non-parametric tests, and quantitative reasoning. Another course mentioned analysis and interpretation of data as well as data collection. This same course described American Psychological Association (APA) citations and references would be covered and expected to be mastered. No coverage of research methodology was apparent in any of the syllabi. Lastly, the textbooks used in these courses were examined. The following text titles were used:

- Introductory statistics

- Publication manual of the American Psychological Association.

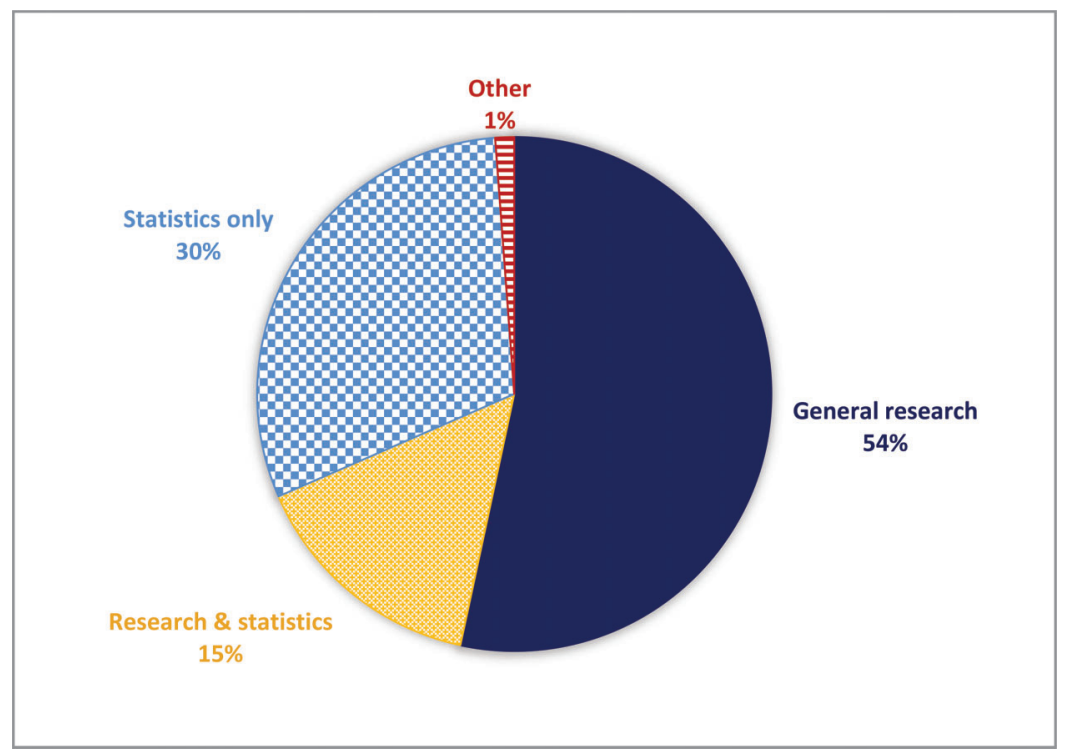

Figure 5. Percent distribution of graduate research course content. 


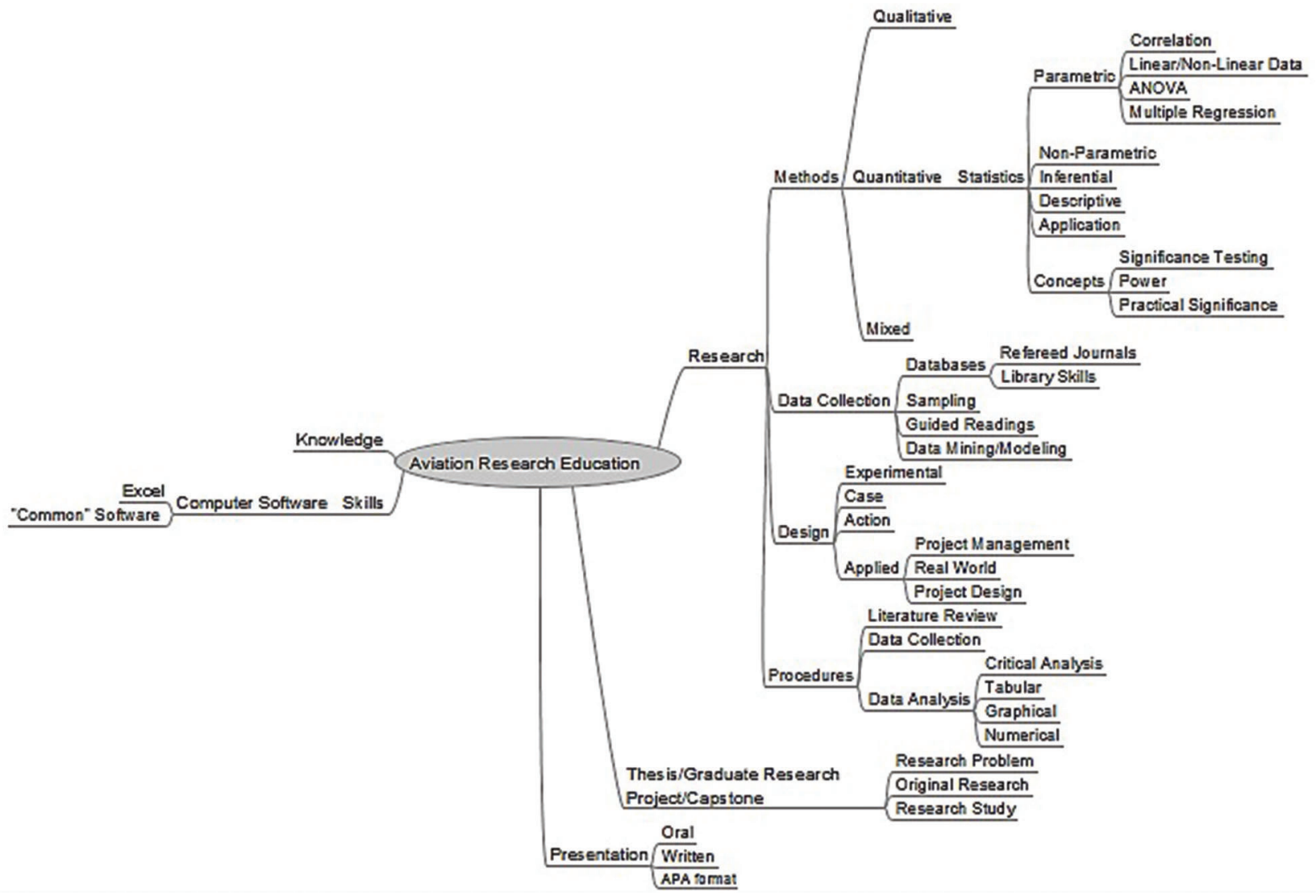

Figure 6. Mind map of themes identified in aviation-specific graduate course descriptions.

\section{Graduate course syllabi}

The eight graduate syllabi analyzed were much more specific in terms of the content covered. In addition, there was much more focus on research method, design, and statistical analysis compared to the undergraduate syllabi. Major themes common among the graduate syllabi were coverage of research design and methodology, statistical analysis, proposal development, research questions, written and oral presentations, and attention to formatting. Some syllabi were more specific about research and included the following in addition to the aforementioned focus areas:

- Collection of data

- Ethics in research

- Independent and dependent variables

- Validity

- Reliability

- Literature reviews

- Experimental research

- Populations and samples

- Sampling

- Controls.

Statistical instruction appeared to be more thorough in the graduate courses. Although only half of the syllabi included detail about the types of statistical analysis that would be covered, all mentioned statistical analysis as a subject area. The following were mentioned specifically among the syllabi:

- Descriptive statistics

- Inferential statistics

- Correlation

- Statistical significance.

In three of the syllabi, more advanced statistics were explicitly described. Among these syllabi, the following tests were mentioned:

- Confidence intervals

- $t$-test

- ANOVA: one-way and factorial

- Multiple regression

- Chi-square

- RBANOVA

- SPANOVA

- ANCOVA.

One course specifically mentioned the attainment of confident use of SPSS software. The functions that students were required to learn to use in SPSS were:

- Descriptive statistics

- Graphing 
- Interpreting results

- Parametric and non-parametric tests.

Other subjects that were covered were APA formatting rules and instrument development.

The evaluation of performance in the courses varied. All courses employed some form of a writing exercise that was a portion of the course grade. Also, a majority included exams or quizzes for assessment. One particular course had a wide range of tasks that included group and individual projects as well as oral presentations. Few courses required practical application exercises, however, with the majority of statistical analysis tasks being in the form of canned or directed tasks. The textbooks used in these courses were examined. The following titles were utilized:

- Publication Manual of the American Psychological Association

- Scientific Research in Education

- Statistical Reasoning for the Behavioral Sciences

- Design and Analysis of Experiments

- Experimental Design and Analysis

- ANOVA Repeated Measures

- Practical Research: Planning and Design

- Educational Research: Competencies for Analysis and Applications

- Exploring Research Methods with an Aviation Emphasis: A Student Guide

- Writing Empirical Research Reports: A Basic Guide for Students of the Social and Behavioral Sciences

- How to Use SPSS: A Step-by-Step Guide to Analysis and Interpretations.

Undoubtedly, the titles indicated a much more focused and in-depth exploration of research methods including computer-assisted quantitative analysis. Even some of these resources gave only cursory or introductory exposure to specific topics.

\section{Interviews with Aviation Program Directors/Faculty}

Interviews with 11 aviation program directors and faculty members were completed over a six-week period. The results were organized as about undergraduate or graduate education and interview question. Next, responses were analyzed using content analysis to identify common themes.

Interviews with undergraduate aviation program directors/faculty

Responses by undergraduate aviation program directors and faculty were analyzed. Content analysis was used to identify common themes for each interview question.

How do you (or your institution) teach research methods/ skills to students? Only one program identified that they had a dedicated research course. Within this class, students were introduced to mostly quantitative methods with a focus on statistics and related research methods. The remaining programs had no specific research methods, or researchfocused courses. The theme among programs was that only basic research skills were covered or required such as the performance of library research, general writing skills, reading literature reviews, and how to avoid plagiarism, but "no new knowledge" was produced. Some limited exposure to research design and statistics was garnered through the aforementioned activities. The most common research task-oriented coursework was a form of senior capstone class that involved some project that had to be reported upon in written and oral formats. Coursework was focused on industry rather than on research.

What types of research skills do students have to use in such courses? The research skills provided to undergraduate students were limited to writing research papers, performing internet searches, case studies, legal research, and limited data analysis (using Department of Transportation databases). Other types of research that students were exposed to included accident reports, qualitative assessments, financial documents, and legal cases. One class did bring in librarians to explain how to use research databases and the basics of APA format and style. A limited introduction to problem statements, writing literature reviews, basic statistics (e.g., chi-square, $t$-tests, and correlation), and central measures was provided by one of the analyzed undergraduate programs. Some discussion of research quality and evaluation was provided in two of the courses. Lastly, limited coverage of methodological types was provided in one course.

What types of projects or assignments are given in such courses? Assignments in undergraduate courses revolved around writing. Papers ranging from 10 to 50 pages were typical and required a review of the literature. Additionally, capstone projects with more practical implications rather than research focus were common. PowerPoint presentations of either the paper or capstone results were omnipresent. All projects were more industry or instructor driven rather than student or research driven. A limited amount of critiquing and critical thinking was required of students. Lastly, proposal writing was present in half of all cases reviewed.

Do you feel that students are competent researchers following completion of the course(s)? Why or why not? What could be done to change this (if applicable)? Answers to this question were almost all no, except for two. One stated that students were "competent for that level [undergraduate] of project" while another said, "yes, they are competent to enter industry." Other comments included 
that students graduate "with basic research skills" and that they "probably can find things or facts." Another stated that students should be comfortable gaining institutional review board approval. One respondent noted that students were not competent to go on to graduate school but were skilled enough to function in airline operations such as in the role of a pilot.

All individuals noted that more research education was needed at the undergraduate level earlier in the curriculum. Another theme identified was to allow for more studentdriven skill building. There was a variety of other recommendations included in comments including need for more writing courses, inclusion of statistics, more instruction on data analysis, and requirements for more complex projects.

What artifacts are collected? The types of artifacts that were collected were papers, presentations, and capstone projects. Papers ranged from 10 to 50 pages. Presentations were required to be conducted in front of groups of peers, faculty, and industry stakeholders. All items were frequently amassed for assessment purposes.

What are the weaknesses of students that you commonly see in these courses? There was a wide range of weaknesses identified, but the most common were poor writing skills and the conduct of plagiarism. Other comments included:

- Not aware of "what research really is"

- Unfamiliar with scientific method

- Preference for quantitative methods (misunderstanding of qualitative methods)

- Finding legitimate sources rather than performing Google searches (e.g., use of Wikipedia)

- Lack of citation skills

- Poor APA skills

- Unable to construct research questions

- Inability to identify a research problem.

What are the strengths of students that you commonly see in these courses? The most frequently identified strength of students was their comfort with using technology. Internet search skill was noted to be very good with a keen ability to find source material. Other strengths included:

- Competent aviation industry knowledge

- Time management skills

- Good presenters

- "Thinking outside the box"

- "Want[ing] to write better"

- "Appreciation for written and oral communication."

\section{Interviews with graduate aviation program directors/ faculty}

Responses by graduate aviation program directors and faculty were analyzed. Content analysis was used to identify common themes for each interview question.
How do you (or your institution) teach research methods/ skills to students? Graduate students received more directed and detailed research instruction. Introduction to statistical methods was universal as was coverage of qualitative and quantitative designs. Guided readings and research were most common with little "actual research" being conducted except at the doctoral level. SPSS and other types of software were mentioned in two courses. APA formatting and style were covered in most courses and were expected to be mastered in all evaluated programs. The most detailed instruction occurred at the doctoral level with 12 to 15 credit hours focused specifically on methods, statistics, and design.

What types of research skills do students have to use in such courses? Graduate students received skill-building guidance in proposal writing, conducting literature reviews, performing ethical research, dealing with institutional review boards, evaluating research quality, and the use of a range of methods and designs. Doctoral-level students received the most detailed instruction typically focusing on the particular method and analysis to be used in the study performed by the student. Statistical analysis instruction was widespread, though only doctoral-level learners appeared to learn how to use more complex analyses (e.g., beyond $t$-tests, correlation, ANOVA, and non-parametric equivalents). Just as among the undergraduate programs, the majority of skill building resided in writing assignments.

What types of projects or assignments are given in such courses? Most assignments were significant writing tasks, namely a capstone project, thesis, or dissertation. Not all master's programs required a thesis per se with one program leaving an option for a comprehensive examination option.

Do you feel that students are competent researchers following completion of the course(s)? Why or why not? What could be done to change this (if applicable)? There was a mixture of positive and negative sentiment about research competence. For master's students, two individuals stated that their graduates were competent researchers. Another stated, "60\% are $40 \%$ are not." At the doctoral level, one stated that even such students were not entirely competent: "students are unfamiliar with studies and methods outside that used in their dissertation." All but one stated that students typically had a higher level of familiarity with qualitative methods than with quantitative. The need for students to have more statistical preparation was mentioned by all but one program stakeholder.

What artifacts are collected? Projects, theses, and dissertations all serve as evidence of competence and completion. 
These milestones were often used to trace tasks back to learning and program outcomes for assessment purposes.

What are the weaknesses of students that you commonly see in these courses? Three major themes emerged from the weaknesses mentioned during the interviews. First was a general debility in statistical knowledge. There were several comments concerning the lack of statistical backgrounds among graduate students. Second, there was a unanimous recognition that student writing was anemic. Third, a deficiency in knowledge of research methods was recognized. Other weaknesses mentioned were:

- Inability to differentiate between "prove" and "statistical significance"

- Poor logic

- Improper or flawed use of references

- Incomplete literature reviews

- Bias towards quantitative methods

- Lack of mathematical preparation

- Problems handling data analysis/improper data anal ysis

- APA style/format errors.

What are the strengths of students that you commonly see in these courses? Two primary themes became apparent from the results of the interviews. One was the recognition that graduate students were "tech savvy"- - they are comfortable with online instruction, databases, and various computer technologies. Another was that students mostly had a good understanding of the aviation industry and were knowledgeable about the subject area of their thesis, capstone, or dissertation. Other strengths included:

- Confidence

- Autonomy

- Persistence.

\section{Discussion}

This study sought to assess and analyze the current nonengineering aviation research methods and skills education landscape to provide an improved understanding of this realm. Throughout the data, a common refrain existed: aviation research education, particularly at the undergraduate level, was in need of strengthening and improvement. Even among graduate programs, deficiencies in student competence in research methods were noted. This is particularly troubling as the literature noted that such lack of skills has a trickle-down effect on the quality and quantity of research studies conducted in a particular subject area.

With only slightly more than a third of programs having research-specific courses and less than 5\% having such courses specifically focused on aviation, it should be no surprise that undergraduates are not exposed to the research skills needed to go on to graduate school or conduct "real" research in the field. Although things appeared to be better among graduate programs with a near majority of having research-oriented courses, less than half had aviationfocused research courses. Although general research skill building is helpful, there are certain aspects unique to the aviation industry that would benefit from more directed coursework.

\section{Findings for Undergraduate Courses}

Undergraduate aviation research education appeared to concentrate on introductory and cursory treatments. Although there were many mentions of statistics, the coursework did not appear to be in-depth or comprehensive. Considering that all assignments in the research classes among these programs were instructor and industry driven, little, if any, engagement or immersion in research occurred. No collaboration with faculty appeared to exist, and students were not readily recruited to assist in actual research projects being conducted at the participating institutions. As noted by Healy et al. (2010) and LaBeouf (2011), the lack of research-led philosophies was likely one of the primary reasons why graduates were not considered to be competent researchers and why entrants to graduate school have been determined to have deficient preparation for the rigor of such programs. Although the course descriptions indicated that a broad spectrum of research-oriented subjects was covered, the premise of this education seemed to revolve around primer material and writing rather than performance and practice. Little attention was given to APA protocol, style, and format commonly used in aviation research. This paucity has caused issues as students migrate up to the graduate level. As described by España (2004), undergraduate aviation research education does not go beyond the dualism phase. Without exposure to the skills and practice of conducting real-world research, students lack the building blocks mentioned by Pato and Pato (2001) to become capable researchers.

Program directors and faculty reinforced the contents uncovered in the course materials. Little or no coverage of research methods was provided, and quantitative methods took precedence. Again, research education seemed preliminary, not preparatory and there was a dearth of application of what was taught. The term research seemed to be most equated to "looking things up" or "finding sources" rather than production of "new knowledge." Writing was the primary means of assessment even because deficient writing was a common complaint about student skill sets. The admission that students are not aware of the true nature of academic "research" and that there were issues concerning the construction of research questions and defining research problems bodes poorly for producing competent student researchers. Another problem area, plagiarism, was prevalent 
and speaks to the need for improved education about paraphrasing, proper citation techniques, and formal writing proficiency. Undergraduate students are comfortable with technology and have a good sense of the aviation industry. These attributes should be used to help in the research education improvement process.

\section{Findings for Graduate Courses}

At the graduate level, the students were exposed to a more comprehensive variety of research subject matter. In-depth coverage or entire courses were dedicated to qualitative, quantitative, and mixed methods. There were more aviation-specific research courses allowing for a more focused inquiry into aerospace subjects. The numbers of different topics and methods covered were also much more varied with an even more quantitative direction. Instruction on and the use of more advanced statistical methods were customary. Analysis software, including SPSS and other data analysis software, received more coverage. Taking the building-block approach advocated by Pato and Pato (2010) even further, several programs had dedicated aviation research methods/design and statistics courses. Doctoral classes had the most advanced coursework with improved exposure to qualitative and alternative methods, experimental designs, and complex statistical analyses. The density and inclusiveness of subjects covered were related by the mind map produced from the data of this study. Unfortunately, many of these courses measured mastery through tests, assignments, and papers rather than the conduct of practical research or collaboration with faculty and peers. This precedent is in direct contrast to the findings of Sullivan and Maxfield (2003) in that students are not being exposed to the research paradigm. Such exposure has been theorized to be necessary to gain the experience and comfort indispensable to become skilled scholars.

Interviews with stakeholders yielded similar results regarding reported subject coverage. At all levels of graduate education, there were some reservations made about claiming competence in research skills among students. Even considering a strong bias towards quantitative methods, one major theme among weaknesses was that students still lacked a good understanding of statistics particularly in the application thereof. Writing ability was also noted as an infirmity. Further, knowledge and practice of research methods were identified as problematic, particularly once exiting a student's comfort zone (i.e., in areas outside the method(s) used in their capstone, thesis, or dissertation). Therefore, a range of learning was still necessary for graduating students to become proficient scholars. Basic deficiencies in research skills such as APA errors, inability to analyze data, and incomplete literature searches were also mentioned. In terms of strengths, graduate students exhibited high competence in the use of technology and were well versed in their area of interest within aviation.

\section{Unique Findings}

Although there were significant similarities among programs at all education levels, there were some exceptional cases that merit inclusion. One undergraduate program was introducing more research coursework to better support their senior capstone project. Due to the poor quality of student performance in this culminating course, the institution was in the process of adding a statistics application and research design class that was specifically aviation centered. One program aspired to have the best writing program in aviation. Students in this undergraduate program are exposed to research and writing in their first aviation course. Some of the tasks to which they are introduced included peer-reviewed research, annotated bibliographies, and writing skills. Students are required to turn in multiple drafts of papers. Further, their papers are sent through plagiarism detection software. The final product must exceed a 12th-grade reading level according to the Flesch-Kincaid readability index (an evaluative tool available in Microsoft Word). The culminating event is the senior capstone project that serves as an assessment of the research and writing threads that run through the program. The project must also be presented to a panel of major airline and industry executives as well as aviation-related government personnel. Furthermore, students participate in poster sessions like that advocated by Crull and Collins (2004). These activities provide some academic socialization necessary for students to become confident and competent researchers (Sullivan \& Maxfield, 2003).

\section{Conclusions}

The consensus of data uncovered in this study indicated that aviation research education is still in a nascent phase. It is evident that undergraduate students have not been receiving the essential exposure to research methods and skills. The existing model relies on outside sources for research education; clearly, aviation programs lean too heavily on other departments such as English and mathematics to teach the necessary expertise. The sentiment among faculty and program leadership favored a bolstering of research skill building throughout the undergraduate level. Additionally, they stated a need for this activity to occur early on within the curriculum, as what few encounters with research do occur seem to currently take place in the senior year. Practical application also was lacking. It is difficult to surmise how students are to learn how to conduct research when they are only tasked with writing papers or taking exams. Faculty needs to involve students in their research and encourage independent inquiry as early in a student's progression as possible.

Even graduate education is ostensibly in need of enhancement. This issue was undoubtedly related to the problems at the undergraduate level highlighted by the data. There 
was no evidence that instruction on quality, academic writing was given except for the limited feedback one may receive on a writing assignment. As is the case in many courses and programs, writing assignments are crowning events; therefore, little time remains to provide ample criticism. Much of the task loading lacks practical application and is highly instructor-led. Students would benefit from a stepping-stone approach as they progress through a program with courses that not only convey subject matter but also require the exercising of gradually more complex research skills. Primarily, it appears goals of research dexterity improvement should exist in most if not all courses.

Lackluster writing and problems with plagiarism were both evident among all programs and at all levels. The cycle shared among programs was that students were exposed to writing in English courses and through minor assignments in both aviation and non-aviation classes. Seemingly, students were expected to simply produce although little instruction or guidance was given on how to write well. Students were expected to construct a well-crafted piece of the cogent and logical script but do not seem to be given the necessary tools to advance their talent. The cycle frequently ended with a large research project in a capstone or culmination course normally in the last two terms. Complaints about student performance in these courses point to the need for more instruction on research methods, writing, style, and format. Directive and practical application tasks should be added to make inroads towards improved writing. Related to this, of course, is plagiarism. Students are not being given the requisite education on how to paraphrase, summarize, and cite research material. Exacerbating this is the widespread use of the internet and electronic sources making cut and paste very tempting and easy to do. Unfortunately, this plagues later stages in a student's education and rears itself even at the capstone level. If left unchecked, this can (and has) trickled into graduate education or academia.

In summary, it is evident that students need to be exposed to research earlier, more frequently, and in further detail than what is currently occurring. Initiatives to help students become involved with research being conducted by faculty should not only be encouraged but should be required. Only by conducting real, relevant studies can a student learn the skills necessary to become a successful scholar. A building-block approach would be the logical means of preparing students to conduct research. Of course, concentrated efforts must also develop firm writing skills. This requires exposure to the type of writing that is expected in the field, meaning students must be immersed in the literature. Then they will need practice to assist in the transition from high school style writing to academic prose. Even an undergraduate who has no intention of going to graduate school would benefit from such edification. Few occupations have career ladders that do not entail some level of investigation or exploration optimized using research skills and tools. Weakness in student research competence was a common and constant complaint among faculty and program directors. Nevertheless, it is unfair to mull over this predicament without recognizing the reason for such faults. Research education is a necessary component of all programs at all levels. Only through improvements can progress be expected towards graduating future scholars.

\section{Recommendations for Future Research}

These findings should be of interest to aviation program administrators to ensure that their programs are in line with the best practices being conducted at peer institutions. Faculty will also be able to use the findings to examine how their courses compare to those at other programs. In light of the conclusions and findings of this study, the following recommendations for future research are suggested:

1. Conduct a study of student perceptions about research education to discover the learner's perspective of this research problem.

2. Perform a study to identify best practices in research education. Possible methods include a Delphi panel, a blog, or focus groups.

3. Broaden the current study to provide a more comprehensive look at syllabi and faculty sentiments.

4. Survey graduates and industry managers to see what research skills are being used on the job and the types of strengths and weaknesses that have been identified in workplace research.

5. Study publication productivity of graduates in an effort to identify which factors or skills best benefit individuals to foster successful publication.

\section{Appendix A}

Participating Institutions: Interviews and Syllabi

- City University of New York (York College)

- Embry-Riddle Aeronautical University

- Florida Memorial University

- Lewis University

- Middle Tennessee State University

- Ohio State University

- Oklahoma State University

- Rocky Mountain College

- Saint Louis University

- University of Maryland Eastern Shore

- University of Western Ontario 


\section{Appendix B}

\section{Interview Protocol}

Thank you for helping me by sharing your experiences in how research methods and skills are taught in aviation programs. This interview process does not have any known harmful effects. Benefits of the process include the potential improvement of the survey you received which will lead to a better understanding about aviation faculty. Your participation in this process is completely voluntary. By agreeing to complete this interview process, you are implying your consent to participate. Does this meet with your approval? Good.

Just as a reminder, I am taking records of our interview session. Following the interview, I will email you a copy of this for your review. Is this acceptable to you? Thank you!

What I am interested in learning during this interview process is how research methods and skills are at your institution.

Please feel free to give me as much detail about your feelings, experiences, and suggestions as you are willing to offer. I am very much interested in your thoughts, ideas, and perspectives. Before we begin, do you have any questions? So, you are ready to start?

1. How do you (or your institution) teach research methods/skills to students?

2. What types of research skills do students have to use in such courses?

3. What types of projects or assignments are given in such courses?

4. Do you feel that students are competent researchers following completion of the course(s)? Why or why not? What could be done to change this (if applicable)?

5. What artifacts are collected?

6. What are the weaknesses of students that you commonly see in these courses?

7. What are the strengths of students that you commonly see in these courses?

\section{References}

Anderson, M. J. (2011). The scientific research method as a learning tool in higher education. Proceedings from the 19th Annual BollingerRosado Teaching \& Learning Effectiveness Symposium: The Scientific Research Method as a Learning Tool in Higher Education. Orlando, FL: Embry-Riddle Aeronautical University.

Berg, B. L. (2007). Qualitative research methods for the social sciences (6th ed.). Boston, MA: Allyn \& Bacon.

Creswell, J. W. (2003). Research design: Qualitative, quantitative, and mixed methods approaches (2nd ed.). Thousand Oaks, CA: Sage.
Crull, S. R., \& Collins, S. M. (2004). Adapting traditions: Teaching research methods in a large class setting. Teaching Sociology, 32(2), 206-211.

Drisko, J. W. (2008). How is qualitative research taught at the master's level? Journal of Social Work Education, 44(1), 85-101.

Embry-Riddle Aeronautical University. (2009). Embry-Riddle launches its first two Ph.D. degree programs to meet new challenges in aviation/ aerospace industry. Retrieved from http://www.spaceref.com/news/ viewpr.html?pid=28811

España, J. (2004). Teaching a research-oriented, graduate global marketing course to adult learners in a one-month format. Journal of American Academy of Business, Cambridge, 4(1/2), 418-422.

Healy, M., Jordan, F., Pell, B., \& Short, C. (2010). The research-teaching nexus: A case study of students' awareness, experiences, and perceptions of research. Innovations in Education and Teaching International, 47(2), 235-246.

Ison, D. C. (2009). Pathways to the aviation professoriate: An investigation into the attributes and backgrounds of professional pilot education faculty. Collegiate Aviation Review, 27(2), 28-44.

Ison, D. C. (2010). Instrument pilot course syllabi: A content analysis. Collegiate Aviation Review, 28(2), 16-31.

Ison, D. C. (2011). Higher education professional pilot faculty qualifications-Are the stakes rising? International Journal of Professional Aviation Training \& Testing Research, 5(1), 26-45.

Johnson, R., Hamilton, R., Gibson, B., \& Hanna, J. (2006). Usefulness of collegiate aviation publications: What aviation educators say. Collegiate Aviation Review, 24(1), 82-100.

Krippendorff, K. (2004). Content analysis: An introduction to its methodology (2nd ed.). Thousand Oaks, CA: Sage.

Kvale, S., \& Brinkmann, S. (2008). InterViews: Learning the craft of qualitative research interviewing (2nd ed.). Thousand Oaks, CA: Sage.

LaBeouf, J. P. (2011). Research-based student learning at the postsecondary level. Proceedings from the 19th Annual Bollinger-Rosado Teaching \& Learning Effectiveness Symposium: Research-Based Student Learning at the Post-Secondary Level. Orlando, FL: Embry-Riddle Aeronautical University.

Leedy, P. D., \& Ormrod, J. E. (2010). Practical research: Planning and design (9th ed.). New York, NY: Pearson.

Lu, A. S. (2007). Characteristics of introductory research methods courses in mass communication doctoral programs. Journalism \& Mass Communication Educator, 62(3), 289-304.

Neuendorf, K. A. (2002). The content analysis guidebook. Thousand Oaks, CA: Sage.

Ning, M., Murphy, P., \& Jinks, A. (2010). Research engagement and attitudes to teaching research to healthcare students: A questionnaire study of healthcare educators. Journal of Further and Higher Education, 34(4), 537-556.

Okumus, F., \& Wong, K. (2007). A content analysis of strategic management syllabi in tourism and hospitality schools. Journal of Teaching in Travel \& Tourism, 7(1), 77-97.

Pato, M. T., \& Pato, C. N. (2001). Teaching research basics to all residents. Academic Psychiatry, 25(1), 77-81.

Riffe, D., Lacy, S., \& Fico, F. (2005). Analyzing media messages using qualitative content analysis in research (2nd ed.). New York, NY: Taylor and Francis.

Singh, Y. K. (2006). Fundamentals of research methodology and statistics. New Delhi, India: New Age International.

Stangor, C. (2007). Research methods for the behavioral sciences (3rd ed.). Boston, MA: Houghton Mifflin.

Sullivan, C. J., \& Maxfield, M. G. (2003). Examining paradigmatic development in criminology and criminal justice: A content analysis of research methods syllabi in doctoral programs. Journal of Criminal Justice Education, 14(2), 269-285. 
Thompson Rivers University. (n.d.). RSMT 3501 Introduction to research methods. Retrieved from https://www.tru.ca/distance/courses/ rsmt3501.html

University Aviation Association. (2012). Institutional membership list. Retrieved February 1, 2012, from http://uaa.aero/sitefiles/uaa/members/ 2012_02_Inst.pdf

University of North Carolina. (2018). Find research courses. Retrieved from https://our.unc.edu/students/courses/

University of Sydney. (2012). Research skills framework. Retrieved from https://library.sydney.edu.au/help/online-training/research-skillsframework.html

Upchurch, S., Brosnan, C., \& Grimes, D. (2002). Teaching research synthesis to advanced practice nurses. Journal of Nursing Education, 41(5), 222-226.

Weathington, B. L., Cunningham, C. J., \& Pittenger, D. P. (2010). Research methods for the behavioral and social sciences. Hoboken, NJ: Wiley \& Sons.

Weber, R. P. (1990). Basic content analysis (2nd ed.). Newbury Park, CA: Sage.

Wright, S. C. (2005). A conceptual framework for teaching research in nursing. Curationis 28(3), 4-10.
Dr. David Ison is an Associate Professor of Aeronautics for the College of Aeronautics at Embry-Riddle Aeronautical University (ERAU)-Worldwide. $\mathrm{He}$ has a $\mathrm{PhD}$ in Educational Studies/Higher Education Leadership/Aviation Higher Education from the University of Nebraska-Lincoln, a MS in Aeronautical Science from ERAU, and a BS in Aviation Management from Auburn University. He spent 10 years in air carrier operations as a pilot prior to entering aviation higher education in which he has been working for 13 years. He has had numerous publications appear in both peer-reviewed and trade journals, including Journal of Unmanned Vehicle Systems, Collegiate Aviation Review, Journal of Aviation Technology and Engineering, Journal of Aviation/Aerospace Education Research, Journal of Online Learning and Teaching, and Journal of Academic Ethics. $\mathrm{He}$ currently serves as editor of the International Journal of Aviation, Aeronautics, and Aerospace. Additionally, he frequently has presented research at conferences including the Association of Unmanned System Vehicles International, Human-Computer Interaction International, and the Transportation Research Forum. The University Aviation Association (UAA) honored him with the 2012 Sorenson Award, which is "presented to professional educators who have made substantial scholarly contributions to the field of aviation." He is also currently the President of UAA. 